\title{
Performance Assessment of District Energy Systems with Common Elements for Heating and Cooling
}

\author{
Aleksandar Ivančić ${ }^{1, * \mathbb{D}}$, Joaquim Romaní ${ }^{1} \mathbb{D}$, Jaume Salom ${ }^{1} \mathbb{D}$ and Maria-Victoria Cambronero ${ }^{2}$ \\ 1 Thermal Energy and Building Performance Group, Catalonia Institute for Energy Research (IREC), \\ Jardins de les Dones de Negre 1, 08930 Sant Adrià de Besòs, Barcelona, Spain; jromani@irec.cat (J.R.); \\ jsalom@irec.cat (J.S.) \\ 2 ACCIONA, Anabel Segura 11, 28108 Alcobendas, Madrid, Spain; mvcambronero@acciona.com \\ * Correspondence: aivancic@irec.cat
}

check for updates

Citation: Ivančić, A.; Romaní, J.;

Salom, J.; Cambronero, M.-V.

Performance Assessment of District Energy Systems with Common Elements for Heating and Cooling. Energies 2021, 14, 2334. https:// doi.org/10.3390/en14082334

Academic Editor: David Borge-Diez

Received: 12 March 2021

Accepted: 15 April 2021

Published: 20 April 2021

Publisher's Note: MDPI stays neutral with regard to jurisdictional claims in published maps and institutional affiliations.

Copyright: (c) 2021 by the authors. Licensee MDPI, Basel, Switzerland. This article is an open access article distributed under the terms and conditions of the Creative Commons Attribution (CC BY) license (https:/ / creativecommons.org/licenses/by/ $4.0 /)$.

\begin{abstract}
District energy systems, especially those integrating renewables or low exergy sources, have multiple elements for generating heating and cooling. Some of these elements might be used for both purposes: heating and cooling, either simultaneously or alternatively. This makes it more complex to separate the assessment and have a clear picture on performance of cooling service on one side, and heating services on the other, in terms of energy, environmental, and economic results. However, a correct comparison between different district energy configurations or among district energy and conventional solutions requires split assessment of each service. The paper presents a methodology for calculating different district heating and cooling system key performance indicators (KPIs), distinguishing between heating and cooling ones. A total of eleven indicators are organized under four categories: energy, environment, economy and socio-economy. Each KPI is defined for heating service and for cooling service. According to this, the methodology proposes a demand-based and an investment-based share factors that facilitate the heating and cooling KPI calculation.
\end{abstract}

Keywords: district heating; district cooling; renewable energy; key performance indicator; benchmarking

\section{Introduction}

Due to new cooling comfort demands, caused by higher internal heat gains, better insulation, but also by increasing outdoor temperatures due to climate change, the cooling demand of buildings is rising. According to the International Energy Agency (IEA), the use of energy for space cooling is growing faster than for any other end use in buildings. Annual sales of air conditioning devices more than tripled between 1990 and 2016 [1]. The IEA forecasting establishes a baseline scenario, which envisages a further tripling in energy needs for space cooling by 2050 [1]. The climate change may play a decisive role in the cooling demand rise. Yalew et al. [2] analysed results of 220 studies, published between the years 2002-2019, projecting climate change impacts on energy systems generally, including cooling demands. The literature review shows a global consensus on decreases in heating demand in cold regions and increases in cooling demand in warm regions. The most substantial impact on energy demand is anticipated to occur in the hot summer and warm winter climates, particularly in the built environment where the DHC systems are a suitable solution. The anticipated cooling demand change on regional level ranges from a small variation in the regions of Western Europe and Former Soviet Union, to over $20 \%$ increase in Latin America and the Caribbean, Pacific OECD and South Asia. Other recent papers report forecasts of a significant cooling demand rise in historically cold climates. Berardi and Jafarpur [3] performed simulations for 16 building typologies for Toronto (ON, Canada), using different weather files derived from the North American Regional Climate Change Assessment Program [4]. The outcome of their study shows an average cooling demand increase in a range of $15-126 \%$ by 2070 , depending on the baseline climatic file adopted and 
building typology. Yet, the increases in cooling consumption are also expected to depend strongly on socio-economic development [3]. The Netherlands Environmental Assessment Agency maintains that the cooling demand for residential sector would surpass the heating one by around 2060 [5].

Decarbonizing of energy systems in general, and of heating and cooling services particularly, becomes a major challenge. District energy, fed with renewables, low exergy or waste energy sources, is envisaged as an important contributing solution in carbon emission reduction [6].

Due to cooling demand rise, it is expected that many existing district heating (DH) systems are going to be upgraded with district cooling (DC) infrastructure and thus complemented to provide cooling service, while new district energy systems are going to offer both heating and cooling from the beginning. Nowadays, modern 4 th generation district energy systems frequently include both heating and cooling provision to the clients [7]. Also, the 5th generation district energy systems conceptualization takes into account both heating and cooling provision [8].

The assessment of a DHC system, providing both heating and cooling, is becoming more challenging when the same equipment or system elements are used for purposes of producing heating and cooling, either simultaneously or alternatively. This is particularly truth for complex systems, which involves different energy sources and technologies in a single ensemble of a district energy systems. Indeed, many components of such a system may be used for both heating and cooling: reversible heat pumps, heat generation or recovery applied to thermally driven cooling technologies, geothermal probes coupled with ground source heat pumps, and photovoltaics among other. Moreover, a growing endeavour of energy vector coupling, including renewable heat, electricity, green hydrogen, and syngas, is going to lead to even more complex district energy systems.

A split assessment of each service to be provided is needed in order to be able to assess correctly a given complex system, to follow the decarbonizing evolution of an existing DHC over time, to perform a comparison between different district energy configurations or a comparison among district energy and conventional solutions.

The question of DH systems assessment has been treated from the standpoint of tariff benchmarking $[9,10]$, tariffs, cost efficiency and profitability [11] or environmental behavior of systems. Noussan [12] analysed the performance of 140 Italian district heating systems, by calculating the primary energy factor and the $\mathrm{CO}_{2}$ emission factor of the heat supplied to the end-users, using the current methodology defined by the European Standards.

The Euro Heat \& Power (EHP) Association has developed guidelines for evaluation of district heating (DH) systems [13], establishing the KPI which focus on heating supply in terms of renewable energy contribution, non-renewable primary energy and carbon emission factor, for a given district heating system. The EHP set of indicators does not cover economy assessment nor local emissions impact. Kveselis et al. [14] applied EHP guidelines to perform a comparison among 28 Lithuanian DH companies were analysed, where required data about their performance indicators was available through data basis of Lithuanian District Heating Association.

Ghafghazi et al. [15] proposed a multicriteria methodology approach for DH source election. The methodology uses six indicators, three of them quantitative: costs, GHG emissions, particulate matter emission and other three qualitative: maturity of the technology, use of local sources and traffic load. The decision process includes analytic hierarchy process (AHP) which helps to weights the criteria, taking into account different interest groups: developer, environmental group, and community representative group. Pakere et al. [16] suggested the use of a climate index as a common indicator to evaluate the performance of DH system efficiency, environmental impact and sustainability. Seven different criteria are used for the evaluation: share of RES, share of RES CHP, specific $\mathrm{CO}_{2}$ emissions, environmental costs, specific distribution heat losses, primary energy factor and share of heat delivered by industrial activity. The criteria are weighted according to the AHP method which reflects the relative importance of the criteria. In both $[15,16]$ some of the in- 
dicators used are not defined with proper precision: "industrial heat" [16] or has qualitative indicators with binary value-yes/no, which allows subjective interpretation [15].

Volkova et al. [17] proposed a methodology for assessing the transition of the existing systems towards 4th generation DH. The authors use five key performance indicators (KPIs), namely: DH supply and return average temperatures, network effective average heat transmission coefficient, the share of consumers covered by intelligent metering, annual total renewable (non-fuel) energy, CHP heat capacity and the share of short-term thermal energy storage.

After the literature review, we can conclude that: (1) none of the identified district energy system performance assessment methodologies and benchmarking studies include district cooling, even if the cooling is becoming more and more significant part of buildings energy demand, as explained above; (2) comprehensive methodology for performance analysis of combined DHC systems has not been reported within the existing bibliography.

The motivation of the present investigation resides in the need for a proper environmental, but also energy and economic assessment of DHC system performance. An assessment of such kind should provide quantitative information, which is calculated in transparent and traceable manner, by a robust standardized methodology. This kind of assessment may be carried out throughout a set of KPIs. Moreover, besides the assessment of a DHC system with independent infrastructures for, on one side heating and on the other side cooling, the methodology should be capable of assessing correctly the cases where some of the equipment or infrastructure is shared, means used for both heating and cooling purposes. During the accomplished literature review we have identified a lack of methodologies to calculate an appropriate KPI for such a purpose.

It is worth clarifying here that the shared equipment or infrastructure is limited to the production plant for the 3rd and 4th generation systems, as they operate with four pipe networks forming independent loops for heating and for cooling, while for the 5 th generation systems, besides the production plant equipment also the distribution infrastructure may become common.

The present methodology proposes and defines a set of eleven KPIs as a tool for assessing a district energy system (DHC) behaviour in separate fashion for heating service and for cooling service, including the case when both services are sharing some of the system elements. The suggested KPIs are designed to reflect the most significant aspects of a district heating and cooling system behaviour, in terms of energy, environment, economic, and social aspects. Each KPI is defined for heating service and for cooling service. According to this, the methodology proposes a demand-based and an investment-based share factors that facilitate the heating and cooling KPI calculation.

The paper is structured as follows: In Section 2 the methodology is explained, detailing the analysis boundaries and establishes parameters that are later used for KPI definition and calculation, including the share factors. Section 3 is dedicated to the KPI definition and calculation formulas. It includes the definition and description of each KPI, and it is divided in four parts: energy, environment, economics, and socio-economics. The energy chapter presents the indicators for analysing the decarbonisation and implementation of renewables in district energy systems, on one hand establishing the calculation of the renewable energy ratio (RER) and on the other hand indicating its impact on the overall non-renewable energy use. Obviously, the final goal of the implementation of renewables is to reduce the greenhouse gas (GHG) missions and the local pollution. Hence, the environment chapter describes the calculation of the emissions related KPI. On top of achieving the environmental goals, the renewable DHC concept must be made economically feasible, hence the economics section addresses the indicators for measuring the investment required, the operation cost, as well as the cost of energy. Finally, financial evaluation of the DHC cost may not include the overall social economy benefits of introducing renewables, as the reduction of emissions and pollution drops the negative impacts on health and environment. This can be related in reduced cost on the health system, which is introduced in social cost indicator. Section 4 is dedicated to an implementation example which refers 
to the district energy system in Olot (Spain). In Section 5 the proposed methodology is discussed, while in Section 6 summary and conclusions are drafted. The results presented here are the outcome of the wider methodological development carried out within the EU Horizon 2020 research project WEDISTRICT [18].

\section{Methodology}

One of the main principles applied in the KPI definition presented below is to use the existing recognized references as starting point and to relate to established standards in case they exist. Evidently, for some of the KPI there is a need to elaborate new or more precise definitions in order to be able to accomplish the objectives. This is particularly the case for the systems which provide both heating and cooling. We consider this division particularly useful for a complete comparison of different DHC system architectures. Thus, we opt to develop KPI capable of representing both heating and cooling performance in an independent manner.

\subsection{System Boundaries}

As mentioned above, the EHP association developed guidelines for evaluation of DHC, through the Ecoheat4cities project [13]. This considers as system boundaries on one side the primary energy input to the production, including all kinds of thermal energy production plants, comprising also cogeneration and waste energy recovery, and on the other side the energy transfer devices included in the building/client substation. The evaluation scheme proposed in the Ecohet4cities guidelines is shown in Figure 1.

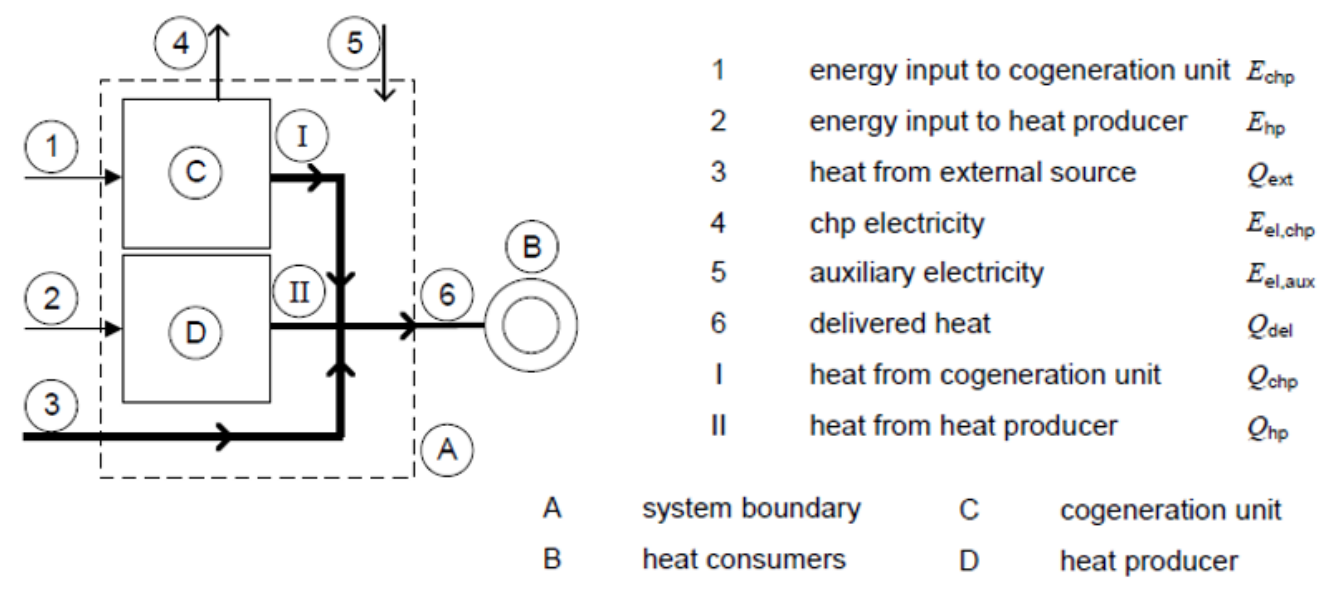

Figure 1. Ecoheat4cities analysis boundaries [13].

The implementation of the EHP boundaries to generic case of extended DHC system is presented in Figure 2, using the set of technologies of WEDISTRICT project. The extended DHC system includes energy harvesting, storage, and conversion. Hence, most of the technologies are included into the production block, comparable to the usual heat only plants (HOP) and combined heat and power plants (CHP), but also including storage technologies and cooling production. Moreover, this approach allows to take into account technologies for energy conversion at user side as well as external heat inputs with waste heat recovery. The definition of the analysis boundaries highlights the importance of defining the evaluation approach of the local, user side, cooling production run by $\mathrm{DH}$, as for example renewable air cooling units (RACU) and the waste heat recovery from different sources, as for example fuel cell powered data centres ( $\mathrm{DaC}+\mathrm{FC}+\mathrm{WHR})$. 


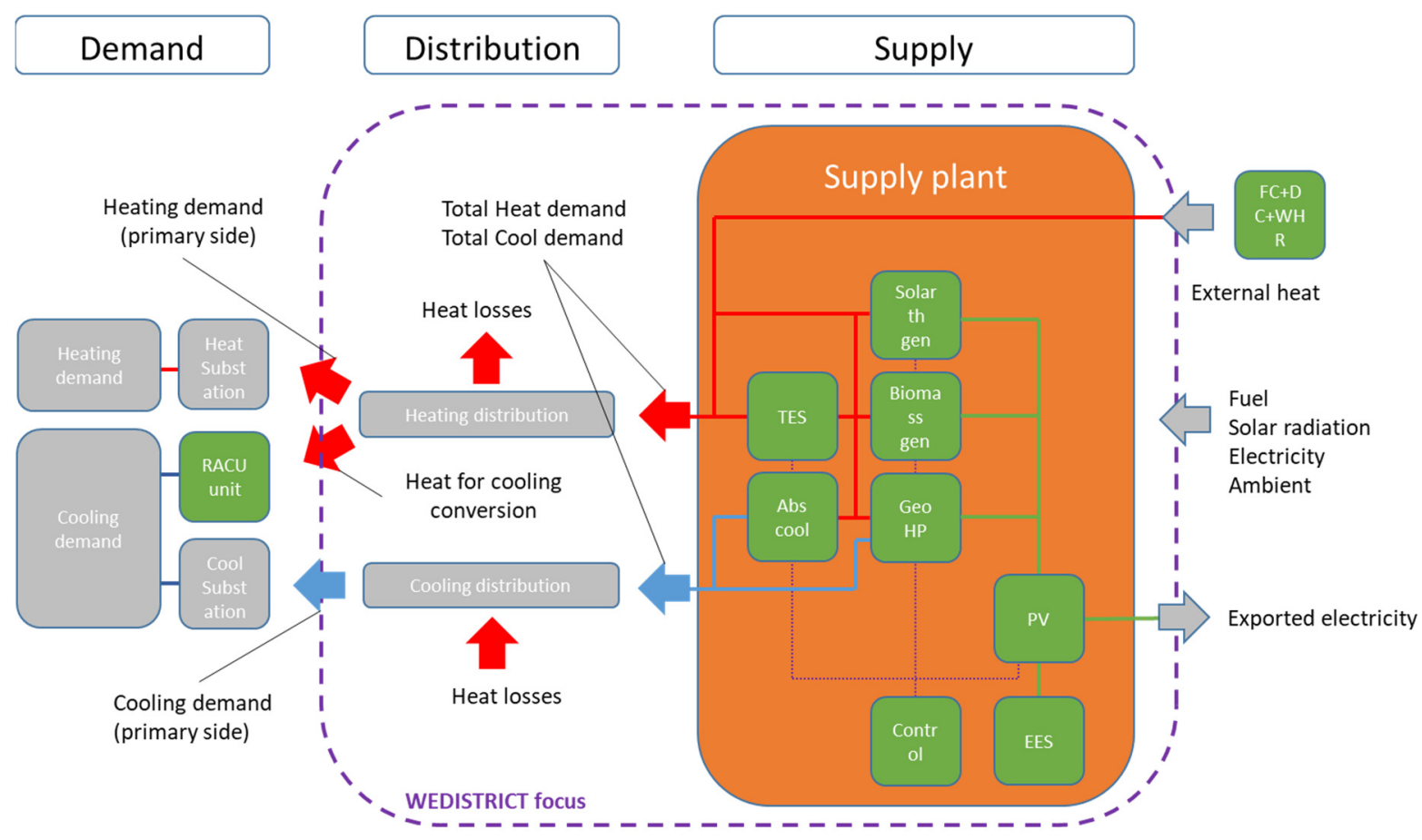

Figure 2. System boundaries example used for analysis of WEDISTRICT projects [18].

Finally, the system level KPIs deal with the evaluation of the performance and impact of overall system during a period of time: namely, one year, or lifetime set to 25 years [19]), from different perspectives: energy, environmental, economic and social one.

\subsection{Limits of Application}

On top of the framework defined in the methodology section, it is important to consider that the calculation of the KPI highly dependent on:

- System technologies configuration.

- $\quad$ Demand profile.

- Network configuration (losses).

- Location (climate).

Cross-comparison of DHC networks KPI cannot be performed directly without considering these dependencies. Obviously, this imply that comparison of different DHC might not be accurate and fair. Hence, the system KPI are better use to assess the evolution and improvement of a DHC compared to previous conditions (in case of retrofitting) or to different configurations when designing a DHC (in case of new systems). Yet, the KPI are proposed as normalized to unit of capacity or demand in order to facilitate the benchmarking.

\subsection{Choice of KPIs}

The present approach follows the general criteria for the energy system sustainability assessment, proposed by Afgan et al. [20]. The authors suggested that system assessment methodologies have to reflect four aspects: resource aspect, environment aspect, social aspect and economic aspect. The set of proposed KPI includes the following ones:

Energy:

- RER Renewable energy ratio (-)

- $f_{n r} \quad$ Non-renewable primary energy factor (-)

Environment:

- $k_{\mathrm{CO}_{2}}$ Equivalent $\mathrm{CO}_{2}$ emission coefficient (g/kWh)

- $k_{x x}$ Pollutant emission coefficients (" $x x^{\prime \prime}$ being $\left.\mathrm{SO}_{\mathrm{x}}, \mathrm{NO}_{\mathrm{x}}, \mathrm{PM}_{2.5}\right)(\mathrm{g} / \mathrm{kWh})$

Economy: 
- CAPEX Capital expenditures $(€ / \mathrm{kW})$

- OPEX $_{f}$ Fixed operational expenditures $(€ / \mathrm{kW})$

- $\operatorname{OPEX}_{v}$ Variable operational expenditures $(€ / \mathrm{kWh})$

- LCOE Levelized cost of energy $(€ / \mathrm{kWh})$

Socio-economic:

- $\quad S C$ Environmental social cost $(€ / \mathrm{kWh})$

The energy aspects assessment is targeting the quantification of renewable energy contribution to a district energy system through Renewable energy ratio, and efficiency of non-renewable resources consumption, through Non-renewable primary energy factor. With the combination of this two KPIs the accomplishment of targets such as ones defined by international energy policies $[21,22]$ are adequately covered.

The environmental KPIs depict the degree of decarbonisation of a district energy system, one of the main challenges of the current net zero policies [22]. Complementary, the emissions of the pollutants with local impact are used to assess the eventual deterioration of the air quality, as the air pollution in cities is a serious threat for human health [23].

The economy aspects are assessed by classical approach to CAPEX and OPEX, as proper indicators for short term vision of a project, but also by Levelized cost of energy which depict the long-term vision of the economy of the project. The systems counting on renewable energy sources frequently needs an important upfront investment which is largely compensate over the project life span. Besides this, the use of economic KPIs that would need the consideration of present or future tariffs, like pay back or internal return rate, are avoided because the tariffs are not necessarily related to the real costs of service [24,25].

As the socio-economic KPI the environmental social cost is included to take into account the externalities related to the climate change and health costs of a system emissions. This cost is usually a hidden cost not reflected on the economic or financial aspects of the energy services, then this are not reflected within the price. Yet, a society ends covering this kind of costs through healthcare expenditure and climate change adaptation.

\subsection{Parameters for Calculating KPI}

In general terms, the KPI may be calculated both using measured data from the field sensors and data acquisition system or calculated data coming from energy system modelling and simulation. This section presents the parameters required for the calculation of the KPI that are: (a) used for multiple indicators, or (2) external to the assessed system.

\subsubsection{Energy Share Factors}

In order to make fair and complete comparisons, among different systems or different technology configurations or system layouts, separating the economic, energy, and environmental impact of the heating and cooling is necessary yet not evident. Therefore, a cooling share factor is proposed for dividing the impact of the elements that are shared between the cooling and heating. It represents the percentage of the energy, environmental or economic impact of cooling service of the shared elements. The division between cooling and heating impact is based on the energy balance of the system, as shown in Figure 3, and calculated according to Equation (1):

$$
\alpha_{c}=\frac{Q_{\text {gen-cool }}+Q_{T E S-c o o l}}{Q_{\text {gen-cool }}+Q_{T E S-\text { cool }}+Q_{h . d i s}}
$$

where $\alpha_{c}$ : Cooling share (-); $Q_{\text {gen-cool }}$ : Heat supplied by the generator equipment to the cooling generation equipment in the plant side of the district $(\mathrm{kWh}) ; Q_{T E S-c o o l}$ : Heat supplied by the thermal energy storage equipment to the cooling generation equipment in the plant side of the district $(\mathrm{kWh})$ and $Q_{h . d i s}$. Heat supplied to the heating distribution network (kWh). 


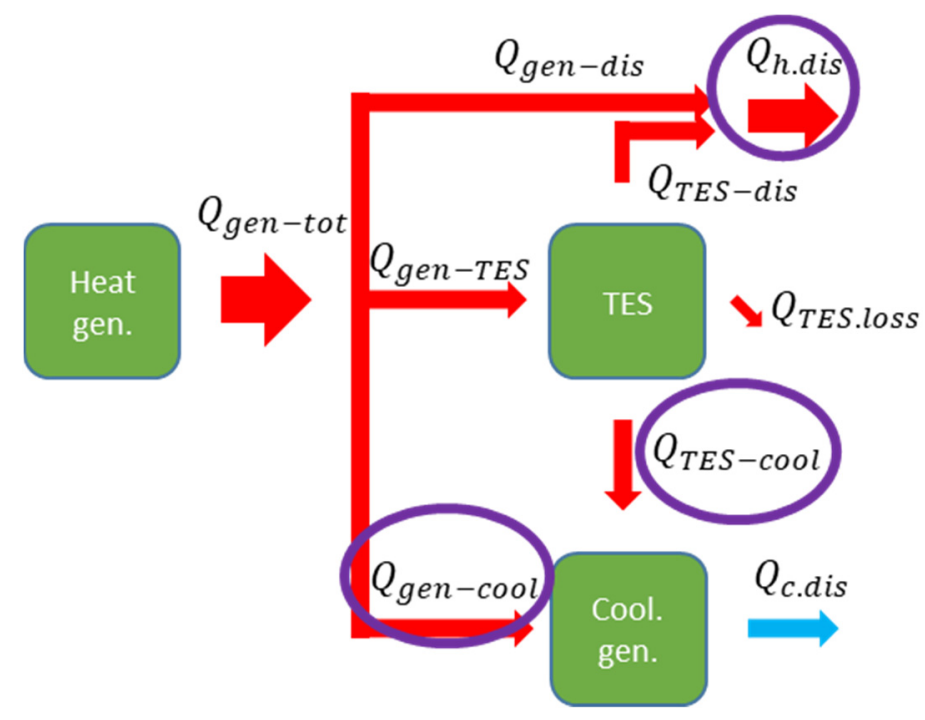

Figure 3. Generic heat fluxes (Highlighted are the fluxes used for the ponderation ratio) [18].

The cooling share factor is used in order to calculate energy, environmental and economic KPIs, always when some common elements exist for both cooling and heating service. Besides this, all other elements (equipment, piping, control system) which are clearly used only for one of the services are assigned totally to the corresponding one.

\subsubsection{Investment Share Factors}

After the present methodology, the CAPEX of the technologies applied for both heating and cooling services should be split after the cooling share factor. Yet, we consider that the rest of the CAPEX components: project engineering, project development, project financing costs, and contingency should be split considering the proportion of the total CAPEX of direct construction costs dedicated, on one side for heating and on another for cooling. For this reason, the investment share factor is introduced, as shown in Equation (2).

$$
\beta_{c}=\frac{C_{d . c}+\alpha_{c} C_{d . h c}}{C_{d . c}+C_{d . h}+C_{d . h c}}
$$

where $\beta_{c}$ : investment cooling share factor; $C_{d . c}$ : Direct construction cost for the equipment used for cooling only $(€) ; C_{d . h}$ : Direct construction cost for the equipment used for heating only $(€) ; \alpha_{c}$ : Cooling share factor $(-)$ and $C_{d . h c}$ : Direct construction cost for the equipment used for both heating and cooling $(€)$.

\subsubsection{Primary Energy Factors}

In general, a DHC system may include energies of different natures and sources. In order to make fair comparisons and to better assess the impact of different system configurations, primary energy is used in the calculations. The primary energy is the energy amount prior to be subject to any conversion or transformation process. According to ISO-52000 [26] the primary energy can be divided into non-renewable and renewable energy, as summarized in Figure 4, if both are taken into account it is referred to as total primary energy. 


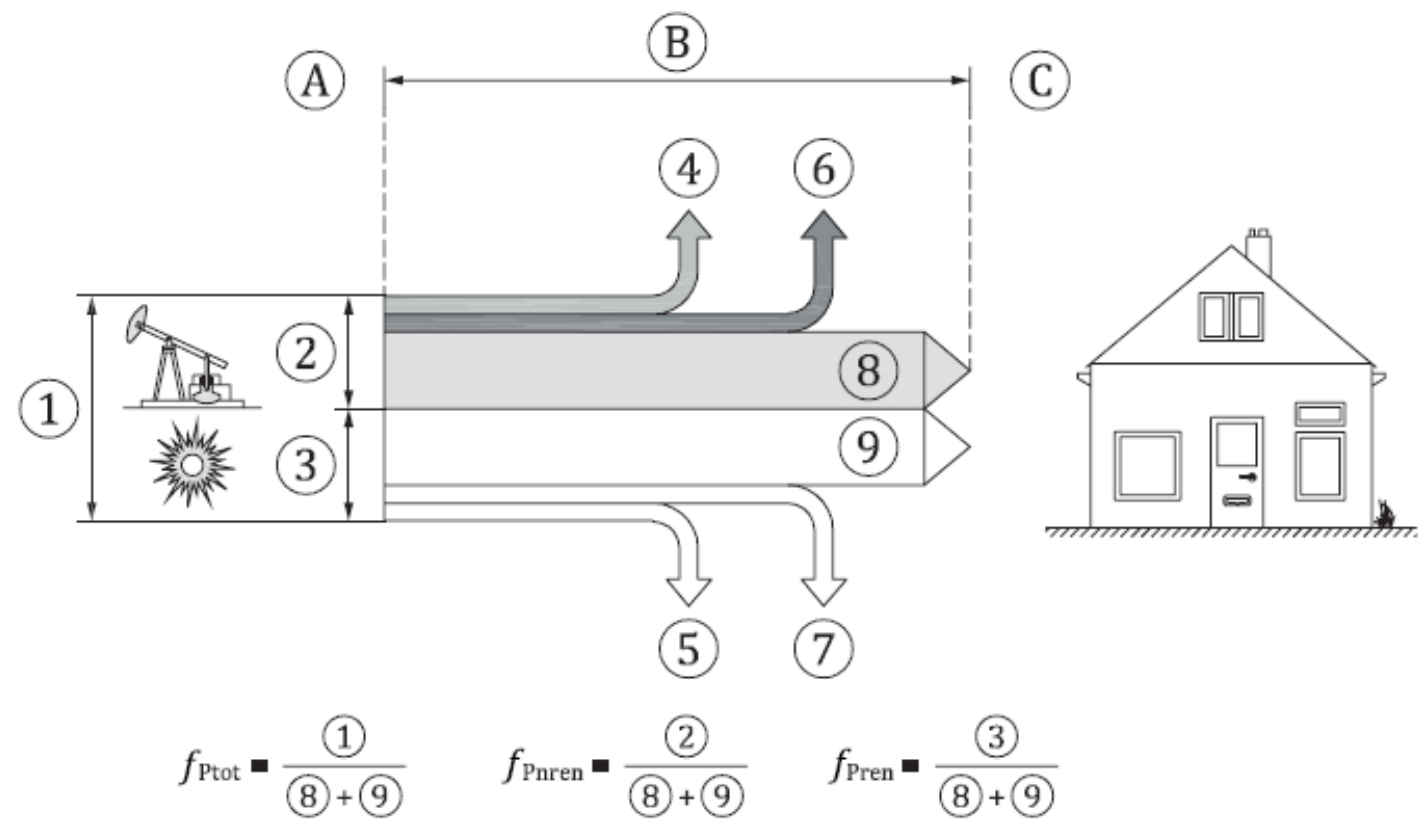

Key

$\begin{array}{ll}\text { A } & \text { energy source } \\ \text { B } & \text { upstream chain of energy supply } \\ \text { C } & \text { inside the assessment boundary } \\ 1 & \text { total primary energy } \\ 2 & \text { non-renewable primary energy } \\ 3 & \text { renewable primary energy }\end{array}$

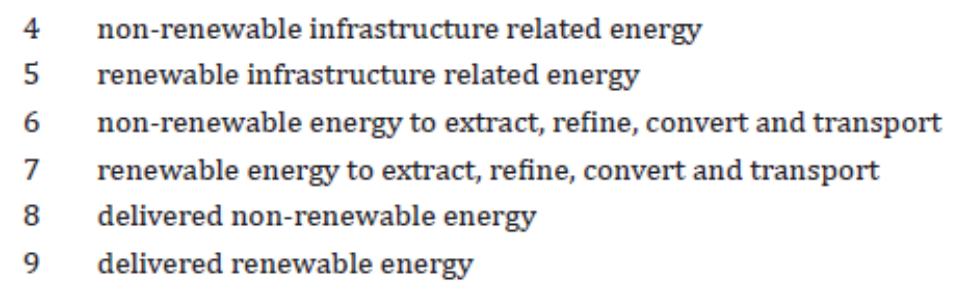

Figure 4. Primary energy factors approach according ISO-52000 [26].

The primary energy factor to be used in the evaluation of systems should ideally come from national statistics and data bases, if available. Otherwise, the ISO proposes generic values [26]. In some cases, the values of the primary energy factor can be dynamic, it may change over time. This is the case of, for example, imported electricity, which depends on the national or regional energy mix at each instant. If available, this kind of data may also be used for more accurate assessment.

For each KPI where the primary energy factors are needed, the KPI description indicate whether renewable, non-renewable, or total primary energy factors are used.

\subsubsection{Primary Equivalent $\mathrm{CO}_{2}$, and Air Pollutant Emission Coefficient}

The emission coefficient refers to the tons released of a pollutant per unit of primary energy of an energy carrier. The primary equivalent $\mathrm{CO}_{2}$ emission coefficient describes the amount GHG of equivalent tons of $\mathrm{CO}_{2}$, while $\mathrm{PM}_{2.5}$ describes the amount of particles of a size smaller than $2.5 \mu \mathrm{m}, \mathrm{NO}_{\mathrm{x}}$ is the weighed sum of $\mathrm{NO}_{2}$ and $\mathrm{NO}$, and $\mathrm{SO}_{\mathrm{x}}$ is related to the sulphur contents of a fuel. These parameters are directly related to the nature of the fuel and to the characteristics of the combustion technology. For the electricity coming for the grid, emission coefficients depend on the energy mix of the region or country.

The proposed approach for the emissions coefficients is the "Tier 3 Technology-specific emission factors" according to IPCC 2019 guidelines [27]. This means using the data provided by the manufacturers according the technology specific KPI. If technology specific data is not available from the suppliers, country specific data or default data from ISO 52000 [26] or IPCC 2019 guidelines [27] may be used for $\mathrm{CO}_{2}$ and GHG emissions, and IEA air pollutant inventory [28] may be used for air pollutants. 


\section{System KPI Definition}

The set of proposed KPI are organised following the aspects of energy resources, environmental aspects, economy questions and social issues. Following sections describes and formulates each one of the KPIs.

\subsection{Energy KPI}

\subsubsection{Renewable Energy Ratio (RER)}

\section{Description}

The renewable energy ratio (RER), or share of renewables, is the fraction of renewable primary energy compared to total primary energy used by the system in order to fulfil the heating and cooling demand.

\section{Calculation}

The Energy performance of buildings directive (EPBD) [29] establishes a definition of the RER for buildings in ISO 52000 [26]. This is adapted to DHC considering the analysis boundaries described in Figure 2. Then the energy fluxes considered are the inputs for the main plant (fuel, electricity imports, solar radiation) and the external heat, while subtracting the electricity exports. The general calculation of the RER is described in Equation (3).

$$
R E R=\frac{E_{\text {Pren }}}{E_{\text {Ptot }}}
$$

where $E_{\text {Pren }}$ : Renewable primary energy used by the district energy network and $E_{\text {Ptot }}$ : Total primary energy used by the district energy network.

Equations (4) and (5) describe the calculation of the RER in separated fashion, for respectively cooling $\left(R E R_{c}\right)$ and heating $\left(R E R_{h}\right)$ generation:

$$
\begin{gathered}
R E R_{c}=\frac{\sum_{i} E_{r . c . i}+\sum_{i}\left(f_{r . i} E_{i . c}\right)+\alpha_{c}\left[\sum_{i} E_{r . h c . i}+\sum_{i}\left(f_{r . i} E_{i . h c}\right)\right]}{\sum_{i} E_{r . c . i}+\sum_{i}\left(f_{t . i} E_{i . c}\right)+\alpha_{c}\left[\sum_{i} E_{r . h c . i}+\sum_{i}\left(f_{t . i} E_{i . h c}\right)-\sum_{i}\left(f_{t . e x p . i} E_{\text {exp. } i}\right)\right]} \\
\operatorname{RER}_{h}=\frac{\sum_{i} E_{r . h . i}+\sum_{i}\left(f_{r . i} E_{i . h}\right)+\left(1-\alpha_{c}\right)\left[\sum_{i} E_{r . h c . i}+\sum_{i}\left(f_{r . i} E_{i . h c}\right)\right]}{\sum_{i} E_{r . h . i}+\sum_{i}\left(f_{t . i} E_{i . c}\right)+\left(1-\alpha_{c}\right)\left[\sum_{i} E_{r . h c . i}+\sum_{i}\left(f_{t . i} E_{i . h c}\right)-\sum_{i}\left(f_{\text {exp. } i} E_{\text {exp. } .}\right)\right]}
\end{gathered}
$$

where $R E R_{c}$ : Cooling renewable energy ratio (-); $R E R_{h}$ : Heating renewable energy ratio $(-) ; E_{\text {r.c. } i}$ : Renewable energy produced by energy carrier " $i$ " and consumed exclusively for cooling generation $(\mathrm{kWh}) ; f_{r . i}$ : Renewable primary energy factor for energy carrier " $i$ " (-); $E_{i . c}$ : Energy produced for non 100\% renewable energy carrier " $i$ " consumed exclusively for cooling generation $(\mathrm{kWh}) ; \alpha_{c}$ : Cooling share factor (-); $E_{r . h c . i}:$ Renewable energy produced by energy carrier " $i$ " and consumed for both cooling and heating generation (kWh); $E_{i . h c}$ : Energy produced for non-100\% energy carrier " $i$ " consumed for cooling and heating generation $(\mathrm{kWh}) ; f_{t . i}:$ Total primary energy factor for energy carrier " $i$ " $(-) ; f_{t . \text { exp. } i}:$ Total primary energy factor of exported energy carrier " $i$ " (-); $E_{\text {exp. } .}$ : Exported energy of carrier " $i$ " $(\mathrm{kWh}) ; E_{r . h . i}:$ Renewable energy produced by energy carrier " $i$ " and consumed exclusively for heating generation $(\mathrm{kWh}) ; E_{i . h}$ : Energy produced for non $100 \%$ renewable energy carrier " $i$ " consumed exclusively for heating generation $(\mathrm{kWh})$.

It should be noted that renewable energy produced by an energy carrier $\left(E_{\text {r.c.i }}, E_{\text {r.h.i. }}\right.$, and $\left.E_{r . h c . i}\right)$ are considered for on-site harvesting of solar, wind, hydro, or ambient energies. The equations effectively consider these renewable energy sources as having a renewable primary energy factor of " 1 ". In contrast, the rest of carriers, which include biofuels and electricity, are considered to have a non-renewable part, hence the corresponding renewable and total primary energy factors are used. Moreover, the energy exports, such as eventual excess of PV or CHP electricity, are considered to compensate the total primary energy use of the DHC with a primary energy factor equivalent to the network carrier.

Finally, according to EU 2018/2001 [30], the HP in heating mode may be considered to harvest renewable energy from the ambient if their coefficient of performance is high 
enough. The method for calculating the renewable energy harvested is presented in Equation (6). This is only applicable if the conditions of Equation (7) are met [30]:

$$
\begin{gathered}
E_{r . H P}=Q_{\text {del }}\left(1-\frac{1}{S P F}\right) \\
S P F>1.15 f_{e l}
\end{gathered}
$$

where $E_{r . H P}$ : Renewable energy harvested by the $H P(\mathrm{kWh}) ; Q_{\text {del }}$ : Delivered useful heat by $H P(\mathrm{kWh}) ; S P F: H P$ seasonal performance factor $(-)$ and $f_{e l}$ : Electricity primary energy factor (-).

\subsubsection{Non-Renewable Primary Energy Factor $\left(f_{n r}\right)$}

\section{Description}

Primary energy accounts for the energy that has not be subjected to any conversion or transformation process. In terms of DHC it is useful for direct comparison with individual heating and cooling systems, as it accounts for all energy chain.

Non- renewable primary energy factor sums up all delivered and exported energy for all energy carries into a single indicator with corresponding primary energy weighting factors. A value of " 0 " indicates a $100 \%$ renewable DHC network.

\section{Calculation}

The calculation of the non-renewable primary energy factor for heating system, according to Ecoheat4cities guidelines [13] is presented in Equation (8).

$$
f_{P, \text { nren }}=\frac{\sum_{i} E_{i} \cdot f_{P, \text { nren }, i}+Q_{e x t} \cdot f_{P, \text { nren,ext }}+\left(E_{e l, a u x}-E_{e l, \text { chp }}\right) \cdot f_{e l}}{\sum_{j} Q_{d e l, j}} .
$$

where $f_{P, \text { nren }}$ : non-renewable primary energy factor $(-) ; \sum_{i} E_{i} \cdot f_{P, \text { nren, } i}:$ energy input $(\mathrm{kWh})$ multiplied by non-renewable primary energy factor (-) of the carrier; $Q_{e x t} \cdot f$ : External heat input (kWh) multiplied by non-renewable primary energy factor (-) of the external heat input; $\left(E_{e l, a u x}-E_{e l, c h p}\right) \cdot f_{e l}$ : Auxiliary electrical energy minus generated electricity $(\mathrm{kWh})$ and non-renewable primary energy factor of electricity $\operatorname{mix}(-)$ and $\sum_{j} Q_{d e l, j}$ : Delivered heat $(\mathrm{kWh})$.

This equation is extended as Equations (9) and (10), which distinguish between the non-renewable primary energy factors for heating service and cooling service:

$$
\begin{gathered}
f_{n r . c}=\frac{\left(\sum_{i} E_{i . c} f_{n r . i}+\sum_{j} Q_{j . c} f_{n r . j}+E_{i m p . c} f_{n r . e l}\right)+\alpha_{c}\left(\sum_{i} E_{i . h c} f_{n r . i}+\sum_{j} Q_{j . h c} f_{n r . j}+\left(E_{i m p . h c}-E_{\text {exp }}\right) f_{n r . e l}\right)}{Q_{c . d e l}} \\
f_{n r . h}=\frac{\left(\sum_{i} E_{i . h} f_{n r . i}+\sum_{j} Q_{j . h} f_{n r . j}+E_{i m p . h} f_{n r . e l}\right)+\left(1-\alpha_{c}\right)\left(\sum_{i} E_{i . h c} f_{n r . i}+\sum_{j} Q_{j . h c} f_{n r . j}+\left(E_{i m p . h c}-E_{\text {exp }}\right) f_{n r . e l}\right)}{Q_{h . d e l}+Q_{h-c}}
\end{gathered}
$$

where $f_{n r . c}$ : cooling non-renewable primary energy factor $(-) ; f_{n r . h}$ : heating non-renewable primary energy factor $(-) ; \alpha_{c}$ : cooling share factor $(-) ; E_{i . c} \cdot f_{n r . i}:$ fuel " $i$ " energy input $(\mathrm{kWh})$ multiplied by corresponding non-renewable primary energy factor (-) of equipment used exclusively for cooling generation; $E_{i . h} \cdot f_{n r . i}$ : fuel " $i$ " energy input $(\mathrm{kWh})$ multiplied by corresponding non-renewable primary energy factor (-) of equipment used exclusively for heating generation; $E_{i . h c} \cdot f_{n r . i}:$ fuel " $i$ " energy input $(\mathrm{kWh})$ multiplied by corresponding non-renewable primary energy factor (-) of equipment used for both heating and cooling purposes (shared); $Q_{j . c} f_{n r . j}:$ external heat $(\mathrm{kWh})$ multiplied by corresponding non-renewable energy factor (-) used exclusively for cooling generation; $Q_{j . h} f_{n r . j}$ : external heat $(\mathrm{kWh})$ multiplied by corresponding non-renewable energy factor $(-)$ used exclusively for heating generation; $Q_{j . h c} f_{n r . j}$ : external heat $(\mathrm{kWh})$ multiplied by corresponding nonrenewable energy factor (-) used for both heating and cooling generation (shared); $E_{e l, i m p . c}$ : 
Electrical auxiliary energy imported from the grid by equipment used exclusively for cooling generation $(\mathrm{kWh})$. It does not include the electrical energy from self-consumption of PV generated electricity; $E_{\text {el, }, i m p . h}$ : Electrical auxiliary energy imported from the grid by equipment used exclusively for heating generation $(\mathrm{kWh})$. It does not include the electrical energy from self-consumption of PV generated electricity; $E_{e l, i m p . h c}$ : Electrical auxiliary energy imported from the grid by equipment used for both heating and cooling generation $(\mathrm{kWh})$. It does not include the electrical energy from self-consumption of PV generated electricity; $E_{e l, e x p}$ : Net exported electricity $(\mathrm{kWh}) ; f_{\text {nr.el }}:$ Non-renewable primary energy factor of electricity mix (-); $Q_{\text {h.del }}:$ Heat delivered to consumers $(\mathrm{kWh}) ; Q_{c . d e l}:$ Cooling delivered to consumers $(\mathrm{kWh})$ and $Q_{h-c}$ : Heat consumed for cooling production at consumer side $(\mathrm{kWh})$.

Note that solar technologies are considered to have a non-renewable primary energy factor of zero, therefore these are not included in the equation. The energy required for heat pumps $(H P)$ or other needs is included in the imported electrical energy. Moreover, usually waste heat recovery from industry is considered fully renewable and then non-renewable primary energy factor is zero. However, in cases of combined heat and power (CHP) the energy factor should be taken into account if the fuel is not renewable. This energy factor must consider the fraction of production of electricity and heat.

\subsection{Environmental KPI}

\subsection{1. $\mathrm{CO}_{2}$ Emission Coefficient $\left(k_{\mathrm{CO}_{2}}\right)$}

\section{Description}

The equivalent emission coefficient represents GHG emissions of a DHC. It is calculated as the primary non-renewable emissions of the greenhouse gasses in terms of $\mathrm{CO}_{2}$ equivalent emissions of a district heating system. Therefore, carbon neutral emissions of biofuels are not taken into account, but emissions related to harvesting of raw material, transformation, and transportation are included.

\section{Calculation}

The calculation of the non-renewable primary emission coefficient extends the equation proposed by Ecoheat4cities guidelines [13] in order to include cooling and the case of shared equipment. The following equations express $\mathrm{CO}_{2}$ equivalent emission coefficients for cooling, Equation (11), and for heating, Equation (12):

$$
\begin{gathered}
k_{\mathrm{CO}_{2 . c}}=\frac{\left(\sum_{i} E_{i . c} k_{i}+\sum_{j} Q_{j . c} k_{j}+E_{i m p . c} k_{e l}\right)+\alpha_{c}\left(\sum_{i} E_{i . h c} k_{i}+\sum_{j} Q_{j . h c} k_{j}+E_{i m p . h c} k_{e l}-\sum_{i} \frac{E_{\text {el.exp }} k_{i}}{\eta_{e l . i}}\right)}{Q_{c . d e l}} \\
k_{\mathrm{CO}_{2} . h}=\frac{\left(\sum_{i} E_{i . h} k_{i}+\sum_{j} Q_{j . h} k_{j}+E_{i m p . h} k_{e l}\right)+\left(1-\alpha_{c}\right)\left(\sum_{i} E_{i . h c} k_{i}+\sum_{j} Q_{j . h c} k_{j}+E_{i m p . h c} k_{e l}-\sum_{i} \frac{E_{\text {el.exp }} k_{i}}{\eta_{\text {el. } i}}\right)}{Q_{h . d e l}+Q_{h-c}}
\end{gathered}
$$

where $k_{\mathrm{CO}_{2} . c}$ : cooling service equivalent $\mathrm{CO}_{2}$ emission coefficient $(\mathrm{kg} / \mathrm{kWh}) ; k_{\mathrm{CO}_{2} . h}$ : heating service equivalent $\mathrm{CO}_{2}$ emission coefficient $(\mathrm{kg} / \mathrm{kWh}) ; \alpha_{c}:$ cooling share factor $(-) ; E_{i . c} \cdot k_{i}$ : fuel " $i$ " energy input $(\mathrm{kWh})$ multiplied by corresponding non-renewable $\mathrm{CO}_{2}$ primary emission coefficient $(\mathrm{kg} / \mathrm{kWh})$ of equipment used exclusively for cooling generation; $E_{i .} \cdot k_{i}$ : fuel " $i$ " energy input $(\mathrm{kWh})$ multiplied by corresponding non-renewable $\mathrm{CO}_{2}$ primary emission coefficient $(\mathrm{kg} / \mathrm{kWh})$ of equipment used exclusively for generation; $E_{i . h c} \cdot k_{i}$ : fuel " $i$ " energy input $(\mathrm{kWh})$ multiplied by corresponding non-renewable $\mathrm{CO}_{2}$ primary emission coefficient $(\mathrm{kg} / \mathrm{kWh})$ of equipment used for both heating and cooling purposes (shared); $Q_{j . c} k_{j}$ : external heat from source " $j$ " ( $\mathrm{kWh}$ ) multiplied by corresponding non-renewable $\mathrm{CO}_{2}$ primary emission coefficient $(\mathrm{kg} / \mathrm{kWh})$ used exclusively for cooling generation; $Q_{j . h} k_{j}$ : external heat from source " $j$ " $(\mathrm{kWh})$ multiplied by corresponding non-renewable $\mathrm{CO}_{2}$ primary emission coefficient $(\mathrm{kg} / \mathrm{kWh})$ used exclusively for heating generation; $Q_{j . h c} k_{j}$ : external heat from source " $j$ " $(\mathrm{kWh})$ multiplied by corresponding non-renewable $\mathrm{CO}_{2}$ primary emission coefficient $(\mathrm{kg} / \mathrm{kWh})$ used for both heating and cooling generation (shared); $E_{\text {el, imp.c }}$ : Electrical auxiliary energy imported from the grid by equipment used exclusively for cooling generation ( $\mathrm{kWh}$ ). It does not include the electrical energy from 
self-consumption of PV generated electricity; $E_{e l, i m p . h}$ : Electrical auxiliary energy imported from the grid by equipment used exclusively for heating generation (kWh). It does not include the electrical energy from self-consumption of PV generated electricity; $E_{e l, i m p . h c}$ : Electrical auxiliary energy imported from the grid by equipment used for both heating and cooling generation $(\mathrm{kWh})$. It does not include the electrical energy from self-consumption of PV generated electricity; $\sum_{i} \frac{E_{e l . e x p} K_{i}}{\eta_{e l i}}$ : Net exported electricity produced with energy carrier " $i$ " (kWh) multiplied by corresponding fuel " $i$ " non-renewable $\mathrm{CO}_{2}$ primary emission coefficient $(\mathrm{kg} / \mathrm{kWh})$, and considering electricity conversion efficiency $\left(\eta_{e l . i}\right)(-) ; f_{e l}$ : Nonrenewable $\mathrm{CO}_{2}$ primary emission coefficient of electricity mix $(\mathrm{kg} / \mathrm{kWh}) ; Q_{h . d e l}$ : Heat delivered to consumers (kWh); $Q_{c . d e l}$ : Cooling delivered to consumers $(\mathrm{kWh})$ and $Q_{h-c}$ : Heat consumed for cooling production at the consumer side (kWh).

In case the electricity is produced only by PV panels its emission coefficient is zero. Yet the PV electricity exports compensates for the emissions related to imported electricity. In terms of Equations (11) and (12) the PV electricity export is considered to have efficiency of " 1 " and an emission coefficient equal to the one of electricity grid.

The emission factor is calculated with an equivalent method to the primary energy coefficient. Solar technologies are considered to have an emission factor of zero, the electricity consumed by the heat pumps is included in the imported electricity. The waste heat recovered is proposed to be considered as renewable, so with emission coefficient of zero. However, emissions from waste heat recovery can be taken into account in cases of external CHP.

\subsubsection{Local Air Pollutants Emission Coefficients}

\section{Description}

The pollutants emission coefficients represent the mass of a particular pollutant that is emitted per unit of energy delivered by a given set of technologies in the system. In general, for DHC systems, the relevant air pollution substances are those related to combustion processes: small particles $\left(\mathrm{PM}_{2.5}\right)$, nitrogen oxides $\left(\mathrm{NO}_{\mathrm{x}}\right)$, and sulphur dioxide $\left(\mathrm{SO}_{2}\right)$.

$\mathrm{PM}_{2.5}$ are small particle with a size inferior of 25 microns strongly related to heart and lung diseases, and affect the crops production. $\mathrm{NO}_{\mathrm{x}}$ are formed in combustion processes due to a combination the oxygen and nitrogen in the combustion air, especially at high temperatures. The coefficient represents a weighted sum of $\mathrm{NO}_{2}$ and $\mathrm{NO}$, where $\mathrm{NO}$ is converted to $\mathrm{NO}_{2}$ in weight-equivalents. $\mathrm{NO}_{x}$ contributes to oxidation of volatile organic compound in a photochemical process which creates ozone. This is related to the formation of smog, hence human respiratory problems and other diseases. It also affects negatively to agriculture due to smog reducing sunlight. Combustion of fuels containing sulphur produces $\mathrm{SO}_{2}$. This has local and regional impacts. On one side, it is related to human heart and lung diseases. Moreover, it causes acidification that affects forests, lakes, and buildings.

The pollutants emissions depend on the fuel as well as the combustion technology. Combustion chamber architectures, catalysts, and filters, among other, affect the pollutants emissions.

\section{Calculation}

The pollutant emission coefficient is the sum of energy input for each technology multiplied by the particle emission coefficients, divided by the total delivered energy. The calculation is carried out according Equations (13) and (14), which are equivalent for all pollutants:

$$
\begin{gathered}
k_{x x . c}=\frac{\left(\sum_{i} E_{i . c} k_{x x . i}+\sum_{j} Q_{j . c} k_{x x . j}\right)+\alpha_{c}\left(\sum_{i} E_{i . h c} k_{x x . i}+\sum_{j} Q_{j . h c} k_{x x . j}\right)}{Q_{c . d e l}} \\
k_{x x . h}=\frac{\left(\sum_{i} E_{i . h} k_{x x . i}+\sum_{j} Q_{j . h} k_{x x . j}\right)+\left(1-\alpha_{c}\right)\left(\sum_{i} E_{i . h c} k_{x x . i}+\sum_{j} Q_{j . h c} k_{x x . j}\right)}{Q_{h . d e l}+Q_{h-c}}
\end{gathered}
$$


where ${ }_{x x}$ : stays for local pollutants considered: $\mathrm{PM}_{2.5}-k_{\mathrm{PM} 2.5} ; \mathrm{NO}_{\mathrm{x}}-k_{\mathrm{NO}} ; \mathrm{SO}_{2}-k_{\mathrm{SO} 2}$; $k_{x x . c}$ : cooling service pollutant " $x x^{\prime}$ " emission coefficient $(\mathrm{kg} / \mathrm{kWh}) ; k_{x x . h}$ : heating service pollutant " $x x^{\prime}$ " emission coefficient $(\mathrm{kg} / \mathrm{kWh}) ; \alpha_{c}$ : cooling share factor $(-) ; E_{i . c} k_{x x . i}$ : fuel " $i$ " energy input $(\mathrm{kWh})$ multiplied by corresponding pollutant " $x x^{\prime \prime}$ emission coefficient $(\mathrm{kg} / \mathrm{kWh})$ of equipment used exclusively for cooling generation; $E_{i . h} k_{x x . i}$ : fuel " $i$ " energy input $(\mathrm{kWh})$ multiplied by corresponding pollutant " $x x^{\prime \prime}$ emission coefficient $(\mathrm{kg} / \mathrm{kWh})$ of equipment used exclusively for heating generation; $E_{i . h c} k_{x x . i}$ : fuel " $i$ " energy input $(\mathrm{kWh})$ multiplied by corresponding pollutant " $x x^{\prime}$ " emission coefficient $(\mathrm{kg} / \mathrm{kWh})$ of equipment used exclusively for both cooling and heating generation; $Q_{j . c} k_{x x . j}$ : external heat from source " $j$ " (kWh) multiplied by corresponding pollutant " $x x^{\prime}$ " emission coefficient $(\mathrm{kg} / \mathrm{kWh})$ used exclusively for cooling generation; $Q_{j . h} k_{x x . j}$ : external heat from source " $j$ " $(\mathrm{kWh})$ multiplied by corresponding pollutant emission coefficient $(\mathrm{kg} / \mathrm{kWh})$ used exclusively for heating generation; $Q_{j . h c} k_{x x . j}$ : external heat from source " $j$ " $(\mathrm{kWh})$ multiplied by corresponding emission coefficient $(\mathrm{kg} / \mathrm{kWh})$ used exclusively for both cooling and heating generation; $Q_{h . d e l}$ : Heat delivered to consumers $(\mathrm{kWh}) ; Q_{c . d e l}$ : Cooling delivered to consumers $(\mathrm{kWh}) ; Q_{h-c}$ : Heat consumed for cooling production at consumer side $(\mathrm{kWh})$.

Note that the pollutants taken into account are considered due to their local impact in health, agriculture, and others. Therefore, the electricity imported from and exported to the grid is not considered in the equations, as it is considered to have a local impact elsewhere. This approach is coherent in order to evaluate the impact of a DHC in terms of local pollution, in comparison to individual systems, which are treated in the same manner.

\subsection{Economy KPI}

3.3.1. Capital Expenditures (CAPEX)

\section{Description}

The capital expenditures (CAPEX) include all the cost involved in acquiring and installing all the assets for starting up the plant, as well as the cost for improving existing assets. This involves:

- Direct construction costs

- Project engineering

- Project development

- Project financing costs

- Contingency

CAPEX is expressed in terms of cost per capacity of the district heating or cooling system $(€ / \mathrm{kW})$. In case the system counts with both heating and cooling, this indicator should be split, having one for providing heating service and another for providing cooling service.

\section{Calculation}

The calculation method is explained for the generic case when both heating and cooling services are provided. Here we suggest splitting CAPEX of the direct construction costs, referred to the shared elements, in a similar way as for the case of energy or environmental KPIs. Thus, the CAPEX of the technologies applied for both heating and cooling services (e.g., solar thermal, mid temperature waste heat recovery, mid temperature storage, etc) should be split after the cooling share factor.

Yet, we consider that the rest of the CAPEX components: Project engineering, project development, Project financing costs, and contingency should be split considering the proportion of the total CAPEX of direct construction costs dedicated, on one side for heating and on another for cooling. The percentages are calculated considering Equations (15) and (16):

$$
C A P E X_{c}=\frac{\left[C_{d . c}+\beta_{c}\left(C_{d . h c}+C_{p e}+C_{p d}+C_{p f}+C_{p c}\right)\right]}{P_{c}}
$$




$$
\text { CAPEX }_{h}=\frac{\left[C_{d . h}+\left(1-\beta_{c}\right)\left(C_{d . h c}+C_{p e}+C_{p d}+C_{p f}+C_{p c}\right)\right]}{P_{h}}
$$

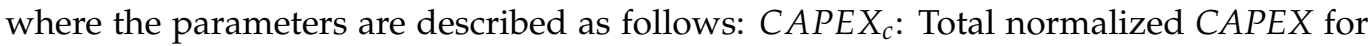
the equipment providing cooling service $(€ / \mathrm{kW}) ; C A P E X_{h}$ : Total normalized CAPEX for the equipment providing heating service $(€ / \mathrm{kW}) ; \beta_{c}$ : CAPEX cooling share factor $(-)$; $C_{d . c}$ : Direct construction costs for the equipment used for cooling only $(€) ; C_{d . h}$ : Direct construction costs for equipment used for heating only $(€) ; C_{d . h c}$ : Direct construction costs for the equipment used for both heating and cooling $(€) ; C_{p e}$ : Project engineering costs $(€)$; $C_{p d}$ : Project development costs $(€) ; C_{p f}$ : Project finance costs $(€) ; C_{p c}$ : Project contingency costs $(€) ; P_{c}$ : Total system cooling capacity $(\mathrm{kW})$ and $P_{h}$ : Total system heating capacity $(\mathrm{kW})$.

\subsubsection{Operational Expenditures (OPEX)}

\section{Description}

The operational expenditures (OPEX) involve the ongoing cost for the operation of the district heating and cooling network, including energy, license, maintenance, labour, utilities, and replacements costs. The OPEX is divided in two parts:

- Fixed operational cost $\left(O P E X_{F}\right)$ : related to the size of the plant and expressed in terms of cost per thermal capacity $(€ / \mathrm{kW})$. It includes:

- Labour cost.

- Maintenance cost.

- $\quad$ Plant performance monitoring costs.

- Indirect operation and maintenance cost (i.e., subcontracted tasks).

- Variable operational cost $\left(O P E X_{V}\right)$ : related to the heating and cooling production of the plant and expressed in terms of cost per thermal energy delivered $(€ / \mathrm{kWh})$. It includes:
- Fuel.
- Electricity.
- Consumables as Chemicals, etc., including their wastes disposal.

\section{Calculation}

For the generic case where the system counts with both heating and cooling, this indicator should be split, having one for providing heating service and another for providing cooling service. All the operational costs are shared in the same way as the total CAPEX. In this way the calculation of fixed operational costs according Equations (17) and (18):

$$
\begin{gathered}
\operatorname{OPEX}_{F . c}=\frac{\left[\sum_{i} O_{F c . i}+\beta_{c}\left(\sum_{i} O_{F h c . i}\right)\right]}{P_{c}} \\
\operatorname{OPEX}_{F . h}=\frac{\left[\sum_{i} O_{F h . i}+\left(1-\beta_{c}\right)\left(\sum_{i} O_{F h c . i}\right)\right]}{P_{h}}
\end{gathered}
$$

where OPEX $X_{F . c}$ : Total normalized fix operational costs for cooling $(€ / \mathrm{kW})$; OPEX $X_{F . h}$ : Total normalized fix operational costs for heating $(€ / \mathrm{kW}) ; \sum_{i} O_{F c . i}:$ Sum of fix operational costs for cooling service only $(€) ; \sum_{i} O_{F h . i}$ : Sum of fix operational costs for heating service only $(€) ; \sum_{i} O_{F h c . i}:$ Sum of fix operational costs shared between heating and cooling $(€) ; P_{c}$ : Total system cooling capacity $(\mathrm{kW}) ; P_{h}$ : Total system heating capacity $(\mathrm{kW})$ and $\beta_{c}$ : CAPEX cooling share factor (-).

While the variable OPEX for cooling and heating are calculated after Equations (19) and (20):

$$
\begin{gathered}
\operatorname{OPEX}_{V . c}=\frac{\left[\sum_{i} O_{V c . i}+\alpha_{c}\left(\sum_{i} O_{V h c . i}-\sum_{i} E_{\text {exp. } i} p_{\text {exp. } .}\right)\right]}{Q_{c}} \\
\operatorname{OPEX}_{V . h}=\frac{\left[\sum_{i} O_{V h . i}+\left(1-\alpha_{c}\right)\left(\sum_{i} O_{V h c . i}-\sum_{i} E_{\text {exp. } .} p_{\text {exp. } . i}\right)\right]}{Q_{h}}
\end{gathered}
$$


where OPEX $X_{V . c}$ : Total normalized variable operational costs for cooling $(€ / \mathrm{kWh}) ; O P E X_{V . h}$ : Total normalized variable operational costs for heating $(€ / \mathrm{kWh}) ; \sum_{i} O_{F c . i}:$ Sum of variable operational costs for cooling service only $(€) ; \sum_{i} O_{F h . i}$ : Sum of variable operational costs for heating service only $(€) ; \sum_{i} O_{F h c . i}$ : Sum of variable operational costs shared between heating and cooling $(€) ; E_{\text {exp. } i}$ : Exported energy of carrier " $i$ " $(\mathrm{kWh}) ; p_{\text {exp. } .}$ : Selling price of exported carrier " $i$ " ( $(/ \mathrm{kWh}) ; Q_{c}$ : Cooling delivered to consumers $(\mathrm{kWh}) ; Q_{h}$ : Heat delivered to consumers $(\mathrm{kWh})$ and $\alpha_{c}$ : cooling share factor (-).

\subsubsection{Levelized Cost of Energy (LCoE)}

\section{Description}

Levelized cost of energy ( $L C O E)$ is a measure of the average net present cost of energy over the system lifetime. It is frequently used to compare technology alternatives for energy generation. $L C O E$ is particularly useful when a high upfront investment is required while a reduced operation costs exist, as it is the case with systems with a high renewable energy share.

The levelized cost of energy calculation is a methodology that discounts the time series of expenditures and incomes to their present values in a specific base year [31]. It provides the costs per unit of energy generated which are the ratios of total lifetime expenses (net present value) versus total expected energy generation, the latter also expressed in terms of net present value. These costs are equivalent to the average price that would have to be paid by consumers to repay all costs with a rate of return equal to the discount rate. NREL proposes a similar approach, which is referred to simple levelized cost of energy (sLCoE) [32], which is an economic assessment of the cost of the energy-generating system including all the cost over its lifetime: initial investment, operations, and maintenance, cost of fuel, and cost of capital, without considering externalities. LCOE is also frequently used for district energy analysis [33-35]. In case the system counts with both heating and cooling, this indicator should be split, having one for providing heating service and another for providing cooling service.

Calculation

Levelized cost of energy (sLCoE) calculation [36] uses Equation (21):

$$
L C O E=\frac{\{(\text { CAPEX } \cdot \text { capital_recovery_factor }+ \text { OPEX } f-\text { final_value })\}}{\left(8760 \cdot \text { capacitiy } y_{\text {factor }}\right)}+\text { OPEXv }
$$

where CAPEX Cost per installed capacity $(€ / \mathrm{kW})$; Capital recovery factor: Ratio of a constant annuity to the present value of receiving that annuity for a given length of time. Considering and interest rate " $i$ " and a number of annuities received " $n$ "; Fixed O\&M: fixed operation and maintenance cost per year related to the installed capacity $[€ / \mathrm{kW} /$ year]; Final value: Residual value of the components at the end of the lifetime of the plant $(€ / \mathrm{kW})$; Capacity factor: Proportion of the year the power plant is generating power; Heat rate: system efficiency, ratio between delivered heat and fuel consumed (-) and Variable O\&M: variable operation and maintenance cost related to the energy production (including fuel cost related to LHV) ( $€ / \mathrm{kWh})$.

The LCOE for a system is calculated in a similar way. For the purpose of clear comparison with conventional technologies, it is distinguished between the heating energy $L C O E$ and cooling energy LCOE as in Equations (25) and (26), respectively:

$$
\begin{gathered}
r v_{c}=\frac{\left[\left(R V_{c}-C_{d e c . c}\right)+\beta_{c}\left(R V_{h c}-C_{d e c . h c}\right)\right]}{P_{c}} \\
r v_{h}=\frac{\left[\left(R V_{h}-C_{d e c . h}\right)+\left(1-\beta_{c}\right)\left(R V_{h c}-C_{d e c . h c}\right)\right]}{P_{h}} \\
C R F=\frac{\left\{i \cdot(1+i)^{n}\right\}}{\left\{\left[(1+i)^{n}\right]-1\right\}}
\end{gathered}
$$




$$
\begin{gathered}
L C O E_{c}=\frac{\left(C A P E X_{c} C R F+O P E X_{F . c}-\frac{r v_{c}}{n}\right) P_{c}}{Q_{c . d e l}}+O P E X_{V . c} \\
L C O E_{h}=\frac{\left(C A P E X_{h} C R F+O P E X_{F . h}-\frac{r v_{h}}{n}\right) P_{h}}{Q_{h . d e l}}+O P E X_{V . h}
\end{gathered}
$$

where $L C O E_{c}$ : Levelized cost of cooling energy ( $\left.€ / \mathrm{kWh}\right) ; L C O E_{h}$ : Levelized cost of heating energy $(€ / \mathrm{kWh}) ; C A P E X_{c}$ : Total normalized CAPEX for the equipment providing cooling service $(€ / \mathrm{kW}) ; C A P E X_{h}$ : Total normalized CAPEX for the equipment providing heating service $(€ / \mathrm{kW})$; OPEX $X_{F . c}$ : Total normalized fix operational costs for cooling $(€ / \mathrm{kW}) ; O P E X_{F . h}$ : Total normalized fix operational costs for heating $(€ / \mathrm{kW})$; OPEX $X_{V . c}$ : Total normalized variable operational costs for cooling $(€ / \mathrm{kWh}) ; O P E X_{V . h}$ : Total normalized variable operational costs of for heating $(€ / \mathrm{kWh})$; CRF: Capital recovery factor: Ratio of a constant annuity to the present value of receiving that annuity for a given project lifetime " $n$ ". Considering and interest rate " $i$ " and a number of annuities received " $n$ "; $r v_{c}$ : Normalized Residual Value of the cooling system components at the end of the considered system lifetime including decommissioning cost $(€ / \mathrm{kW}) ; r v_{h}$ : Normalized Residual Value of the heating system components at the end of the considered system lifetime including decommissioning cost $(€ / \mathrm{kW}) ; R V_{c}$ : Residual value of the cooling specific system components at the end of the considered lifetime $(€) ; R V_{h}$ : Residual value of the heating specific system components at the end of the considered lifetime $(€) ; R V_{h c}$ : Residual value of the system components used for both heating and cooling generation at the end of the considered lifetime ( $€) ; C_{\text {dec.c }}$ : Decommissioning cost of the cooling specific system components at the end of the considered lifetime $(€) ; C_{\text {dec. } h}$ : Decommissioning cost of the heating specific system components at the end of the considered lifetime $(€) ; C_{\text {dec.hc }}$ : Decommissioning cost of the system components used for both heating and cooling generation at the end of the considered lifetime $(€) ; Q_{c . d e l}$ : Cooling delivered to consumers per year $(\mathrm{kWh}) ; Q_{h . d e l}$ : Heat delivered to consumers per year $(\mathrm{kWh}) ; Q_{h-c}$ : Heat consumed for cooling production at consumer side $(\mathrm{kWh}) ; n$ : Lifetime of the system (year); $\beta_{c}$ : CAPEX cooling share factor (-); $P_{c}$ : Total system cooling capacity $(\mathrm{kW})$ and $P_{h}$ : Total system heating capacity $(\mathrm{kW})$.

\subsection{Socio-Economic}

\section{Environmental Social Cost (SC)}

\section{Description}

Environmental and social cost represents the externalities related to the climate change and health costs of greenhouse gas and local health-impact emissions. This comprehends local and global impact. This cost is not reflected on the financial aspects of the energy services, then this are not reflected within the price. Yet, the environmental impacts generate cost to the society related to health and climate change.

On one side, greenhouse gasses emissions, such as $\mathrm{CO}_{2}, \mathrm{CH}_{4}$, and $\mathrm{N}_{2} \mathrm{O}$ are the main cause of global warming and climate change. On the other, $\mathrm{SO}_{2}, \mathrm{NO}_{\mathrm{x}}$, and particles cause local impact mainly related to health issues, such as heart and lung diseases that increase morbidity and mortality, but also acidification impacting forest, lakes and building materials, eutrophication, and generation of smog.

The concept is used in DHC by the Danish Energy Agency LCOE calculator as part of the externalities [33]. Moreover, the concept is in a studies of green building impact in indoor and climate change [36]. Finally, the European Environment Agency presents the cost of air pollution from European industrial facilities [37].

\section{Calculation}

The climate change and health cost KPI is calculated considering the emissions factors of each pollutant, according the corresponding technology KPI, and using the emission cost factors for each pollutant, as described generically in Equation (27):

$$
S C=\frac{\sum_{i} \sum_{x}\left(c_{e . x} \cdot k_{i . x} \cdot E_{i}\right)}{Q_{d e l}}
$$


where SC: Environmental social cost; $c_{e . x}$ : Emission cost of pollutant " $x^{\prime \prime}(€ / \mathrm{kg}) ; k_{i . x}$ : Emission coefficients of pollutant " $x$ " from carrier " $i$ " (kg/kWh); $E_{i}$ : Energy input of carrier " $i$ " and $Q_{d e l}$ : Delivered energy of the system $(\mathrm{kWh})$.

For a relevant carrier and pollutants, the social cost can be calculated according Equations (28) and (29). The emission factors are considered in the same way as in nonrenewable primary energy factor KPI. The emission cost of pollutants may be taken from the data published by the European Environment Agency [37]:

$$
\begin{gathered}
s c_{c}=\frac{\sum_{i} E_{i . c}\left(\sum_{x} c_{e . x} \cdot K_{i . x}\right)+\alpha_{c}\left(\sum_{i} E_{i . h c}\left(\sum_{x} c_{e . x} \cdot K_{i . x}\right)\right)}{Q_{c . d e l}} \\
s c_{h}=\frac{\sum_{i} E_{i . h}\left(\sum_{x} c_{e . x} \cdot k_{i . x}\right)+\left(1-\alpha_{c}\right)\left(\sum_{i} E_{i . h c}\left(\sum_{x} c_{e . x} \cdot k_{i . x}\right)\right)}{Q_{h . d e l}+Q_{h-c}}
\end{gathered}
$$

where $s c_{c}$ : Cooling environmental social cost $(€ / \mathrm{kWh}) ; s c_{h}$ : Heating environmental social cost $(€ / \mathrm{kWh}) ; c_{e . x}$ : Emission cost of pollutant " $x$ " $(€ / \mathrm{kg}) ; k_{i . x}$ : Emission coefficients $(\mathrm{kg} / \mathrm{MWh})$ of pollutant " $x$ " for fuel and combustion technology " $i$ " ( $\mathrm{kg} / \mathrm{kWh}) ; E_{i . c}$ : Energy input of carrier $(\mathrm{kWh})$ " $i$ " used exclusively for cooling generation; $E_{i . h}$ : Energy input of carrier $(\mathrm{kWh})$ " $i$ " used exclusively for heating generation; $E_{i . h c}$ : Energy input of carrier $(\mathrm{kWh})$ " $i$ " used exclusively for both cooling and heating generation; $Q_{h . d e l}$ : Heat delivered to consumers $(\mathrm{kWh}) ; Q_{c . d e l}$ : Cooling delivered to consumers $(\mathrm{kWh})$ and $Q_{h-c}$ : Heat consumed for cooling production at consumer side $(\mathrm{kWh})$.

\section{Implementation Example: Olot (Spain) District Energy}

The Olot (Catalonia, Spain) district heating and cooling system is an example of a small high renewable use network. The district has a generation plant composed of two biomass boilers, three heat pumps coupled with a geothermal field, and PV panels. The heat pumps are providing both heat in winter season and cooling in summer season. Currently five buildings are connected to the network, see yellow connections in Figure 5, with prevision to extend to further clients (red connections).

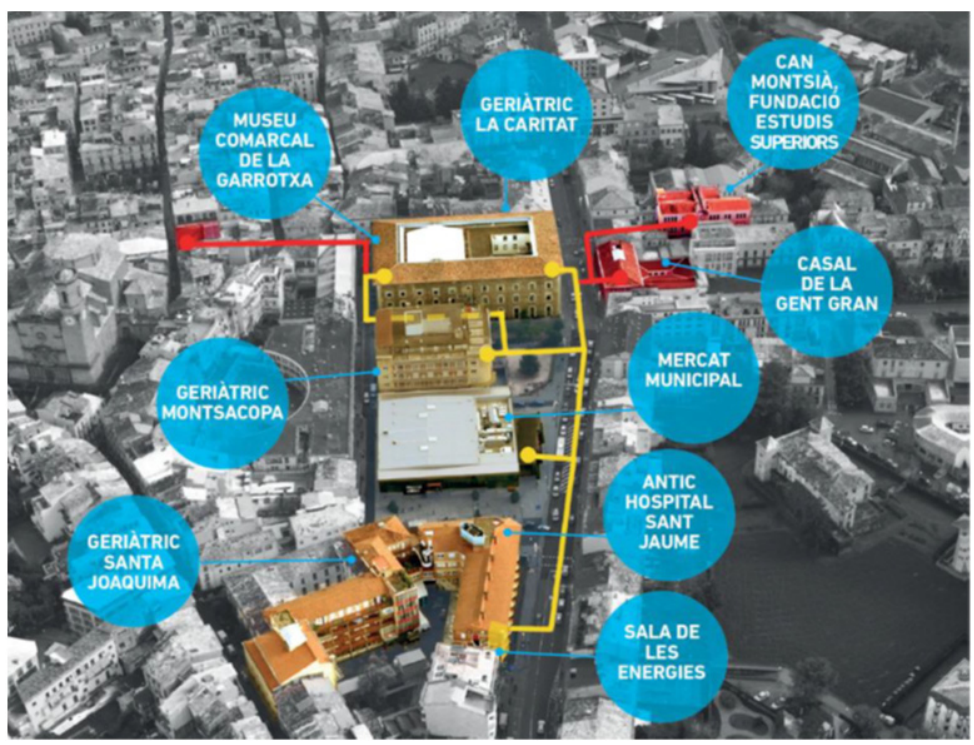

Figure 5. Olot DHC system scheme. Source: Aiguasol.

The Olot DHC concept is somewhat singular, trying to cover previously existing demands in the most efficient manner. It is based on the supply of high temperature heating, low temperature heating and cooling, providing all these services through two loops network (four pipes distribution). One loop is dedicated all year around to the high temperature heat demands (conventional heating systems and domestic hot water) and 
corresponds to the usual heat distribution in DHC systems. The other loop supplies the low temperature demands (floor heating systems) during the winter season and delivers cooling during the summer period.

The KPI input parameters are summarized, in Appendix A, as follows. The delivered thermal energy and both fuel and electricity consumption are described in Tables A1 and A2, with the economic parameters are summarized in Table A3. Finally, the factor for primary energy, emissions, and social cost are taken from ISO52000 [26] and European Environmental Agency [37], as summarized in Tables A4 and A5. As described in the methodology section, the first step in the KPI calculation is to obtain the energy share factor and the investment share factor, according Equations (1) and (2). Being a heating dominant system, heating demand being almost 27 times de cooling demand, and with the equipment serving cooling also used for heating in winter, both share factor have very low values, as summarized in Table 1.

Table 1. Energy and investment share factor.

\begin{tabular}{ll}
\hline$\alpha_{C}$ & 0.036 \\
\hline$\beta_{C}$ & 0.105 \\
\hline
\end{tabular}

With all the data collected and the share factor obtained, the KPI can be calculated. It is important to notice that the district does not export energy outside the system, with all the PV energy used to power the circulation pumps and the heat pump. Moreover, the air pollutants emissions are only considered as local impacts, hence those related to the energy grid are no taken into account in the calculation. This causes the cooling supply to have zero emissions of $\mathrm{NO}_{\mathrm{x}}, \mathrm{SO}_{2}$, and $\mathrm{PM}_{2.5}$ associated to it.

The results are presented in Table 2, showing that the heating part has a higher renewable share, hence lower $\mathrm{CO}_{2}$ emissions. However, as the biomass produces local air pollutants, the social health impact is also much higher.

Table 2. Olot DHC KPI results.

\begin{tabular}{|c|c|c|c|c|}
\hline & KPI & & Cooling & Heating \\
\hline \multirow{2}{*}{ Energy } & Renewable Energy Ratio (RER) & - & 0.199 & 0.939 \\
\hline & Non-renewable primary energy $\left(f_{n r}\right)$ & kWh prim/kWh del & 0.573 & 0.077 \\
\hline \multirow{4}{*}{ Environmental } & Equivalent $\mathrm{CO}_{2}$ emission coefficient $\left(k_{\mathrm{CO}_{2}}\right)$ & $\mathrm{kg} / \mathrm{kWh}$ & 0.097 & 0.027 \\
\hline & $\mathrm{NO}_{\mathrm{x}}$ emission coefficient $\left(k_{\mathrm{NOx}}\right)$ & $\mathrm{kg} / \mathrm{kWh}$ & 0.000 & 0.369 \\
\hline & $\mathrm{SO}_{2}$ emission coefficient $\left(k_{\mathrm{SO} 2}\right)$ & $\mathrm{kg} / \mathrm{kWh}$ & 0.000 & 0.045 \\
\hline & $\mathrm{PM}_{2.5}$ emission coefficient $\left(k_{\mathrm{PM} 2.5}\right)$ & $\mathrm{kg} / \mathrm{kWh}$ & 0.000 & 0.567 \\
\hline \multirow{4}{*}{ Economic } & CAPEX & $€ / \mathrm{kW}$ & 789.7 & 1.139 .0 \\
\hline & Fix OPEX & $€ / \mathrm{kW}$ & 61.95 & 119.76 \\
\hline & Variable OPEX & $€ / \mathrm{kWh}$ & 0.034 & 0.025 \\
\hline & $\mathrm{LCoE}$ & $€ / \mathrm{kWh}$ & 0.288 & 0.092 \\
\hline Social & Social cost $(S C)$ & $€ / \mathrm{kWh}$ & 0.0016 & 0.0445 \\
\hline
\end{tabular}

From the obtained share factors one can observe that the major part of both the energy provided by the system and the investment go for heating service. What we can also see from the results of the present example is that the heating service is almost totally fed with renewable sources $(93.9 \%)$ while the cooling service is much less covered with renewable energy $(19.9 \%)$. Both services perform good in terms of carbon emissions, yet the heating reaches better figure. However, the heating service provokes local pollutants emissions, due to the intense use of biomass. 


\section{Discussion}

By applying the proposed methodology to the Olot example, we can conclude that with a complete overview and the detailed information on the project, the assessment of all the KPIs is clear and straightforward process. Having in mind that the system architecture of this case is not the most common one but rather complex, with shared ground source heat pumps and PV, and a 4-pipe distribution system consisting of one loop for high temperature heating and domestic hot water all year around, and another for low temperature demands (floor heating systems) during the winter season and cooling demands during the summer period.

The introduction of share factors is considered as a major contribution of the present methodology as it permits to assess correctly the common element used for both heating and cooling production and supply. The use of such shared elements adds value to overall district energy system, both in terms of economy by reducing CAPEX and OPEX, as in terms of energy efficiency and environmental impact. In fact, use of heat pumps for simultaneous production of heating and cooling is becoming frequent in big DHC systems [25,38].

The choice of the KPIs is considered appropriate and complete enough for a proper system overall assessment. It provides a tool which can assess the achievement of measurable objectives, which in general terms should be the $100 \%$ or near $100 \%$ renewable energy DHC, or carbon neutral DHC systems, although each case or benchmark study may have it particular objectives.

Yet, the methodology in its present formulation does not facilitate a straightforward benchmarking by comparison of a single unified indicator, like methodologies used in [15] or [16]. Yet, departing from the defined set of KPIs it is possible to apply Analytical Hierarchy Process (AHP) methodology to define the weight factors for each KPI and to calculate a weighted average as the final score of the assessment. If needed, this further step should be performed for each individual assessment case, as the right factors strongly depend the local circumstances and thus of the assessment process targets.

The proposed set of system KPIs is expected to be useful to technology integrators and utilities, but also to public administration, in order to check and benchmark the resource, environmental, economic, and social impacts of the systems. Yet, the proposed assessment methodology of district energy system will become a useful tool only if it proves useful in the engineering practice and energy planning decision making.

\section{Summary and Conclusions}

The DHC planners, utilities and public administration, which are interested in fulfilling the heating and cooling needs with the most environmentally friendly and economically feasible way need a robust and clear benchmarking method. The comparison of different systems may be complex when different conventional and renewable or waste energy sources come into play. The proposed methodology is in line with existing guidelines and standard, mainly incorporating definitions from ISO 52000, Euroheat\&Power association guidelines and the Danish Energy Agency documents. However, most of the literature available is focused in the transformation of a single energy carrier, either electricity or heat. No comparison methodology is available for systems that carry out the combined and/or simultaneous generation of heating and cooling. Consequentially, a method for calculating separately the cooling and heating impact in terms of energy, environment, and economics is proposed. In order to achieve a clear picture on energy, environmental and economic results of each service provided by a DHC with common sources, the share factors based on the energy balance and investment weighting ratio have been defined. With the presented approach a robust and consistent KPIs have been obtained.

Author Contributions: Conceptualization: A.I. and J.R.; Methodology: A.I. and J.R.; Funding acquisition: M.-V.C. and J.S.; Project administration: M.-V.C.; Writing—original draft: A.I. and J.R.; Writing-review \& editing, A.I., J.R. and J.S. All authors have read and agreed to the published version of the manuscript. 
Funding: This work has received funding from the European Union H2020 Framework Programme under Grant Agreement no. 857801 (WEDISTRICT).

Institutional Review Board Statement: Not applicable.

Informed Consent Statement: Not applicable.

Data Availability Statement: 3rd Party Data. Restrictions apply to the availability of these data. Data was obtained from Aiguasol and are available from the authors with the permission of Aiguasol. The data are not publicly available due to privacy.

Acknowledgments: Joaquim Romaní would like to thank Ministerio de Economia y Competitividad de España for Grant Juan de la Cierva FJC2018-038475-I. Authors would like to thank to Aiguasol consultancy for facilitating the raw data of the Olot district energy system.

Conflicts of Interest: The authors declare no conflict of interest.

\section{Appendix A}

Table A1. Delivered thermal energy and total energy consumption for generation.

\begin{tabular}{ccccc}
\hline \multirow{2}{*}{ Parameter } & \multirow{2}{*}{ Units } & \multicolumn{2}{c}{ Heating } & Cooling \\
\cline { 3 - 5 } & & High T & Low T & \\
\cline { 3 - 5 } & & Biomass Boiler & \multicolumn{2}{c}{ Heat Pump } \\
\hline Delivered thermal energy & $\mathrm{kWh}$ & 1.878 .202 & 83.663 & 72.300 \\
\hline Transformation efficiency & - & $85 \%$ & COP 4.95 & EER 4.46 \\
\hline Fuel consumption & $\mathrm{kWh}$ & $2.209 .649 *$ & $-{ }^{* *}$ & $-*$ \\
\hline${ }^{*}$ Biomass, equivalent to 643.313 kg. ${ }^{* *}$ Electricity. & & &
\end{tabular}

Table A2. Electricity energy consumption.

\begin{tabular}{ccccc}
\hline \multirow{2}{*}{ Parameter } & Units & \multicolumn{2}{c}{ Heating } & \multirow{2}{*}{ Cooling } \\
\cline { 3 - 5 } & & High T & Low T & \\
\cline { 3 - 5 } & & Biomass Boiler & Heat Pump \\
\hline $\begin{array}{c}\text { Power consumption for thermal } \\
\text { conversion }\end{array}$ & $\mathrm{kWh}$ & - & 16.902 & 16.229 \\
\hline Power consumption for pumping & $\mathrm{kWh}$ & 56.346 & 7.530 & 6.507 \\
\hline Power supplied by PV & $\mathrm{kWh}$ & 41.510 & - & 1.530 \\
\hline Power supplied by grid & $\mathrm{kWh}$ & 14.836 & 7.530 & 4.977 \\
\hline
\end{tabular}

Table A3. Economic parameters.

\begin{tabular}{ccccccc}
\hline \multirow{2}{*}{ Parameter } & & Units & Total H\&C & $\begin{array}{c}\text { Heating } \\
\text { Only }\end{array}$ & $\begin{array}{c}\text { Common } \\
\text { H\&C }\end{array}$ & $\begin{array}{c}\text { Cooling } \\
\text { Only }\end{array}$ \\
\hline \multirow{3}{*}{ CAPEX } & Direct costs & $€$ & 1.023 .441 & 269.411 & 641.921 & 85.109 \\
\cline { 2 - 7 } & Other costs & $€$ & 43.400 & - & 43.400 & - \\
\cline { 2 - 7 } & Total & $€$ & 1.066 .841 & 296.411 & 685.321 & 85.109 \\
\hline \multirow{2}{*}{ OPEX } & Fix & $€ / \mathrm{kW}$ & - & 11.523 & 89.458 & 2.553 \\
\cline { 2 - 7 } & Decommissioning & $€ / \mathrm{kWh}$ & - & 9.181 & 13.669 & 496 \\
\cline { 2 - 7 } & Residual value & $€$ & - & 41.349 & 96.629 & 27.556 \\
\cline { 2 - 7 } & Variable & $€ / \mathrm{kWh}$ & - & $48.918 *$ & - & $2.439 * *$ \\
\hline
\end{tabular}

* Biomass cost. ${ }^{* *}$ Electricity cost. 
Table A4. Primary energy and emission factors.

\begin{tabular}{ccccc}
\hline Parameters & & Units & Biomass & Electricity \\
\hline \multirow{2}{*}{$\begin{array}{c}\text { Primary energy } \\
\text { factor }\end{array}$} & Renewable & $\mathrm{kWh}$ prim/kWh final & 1.003 & 0.414 \\
\cline { 2 - 5 } & $\mathrm{Non}-$ renewable & $\mathrm{kWh}$ prim/kWh final & 0.034 & 1.954 \\
\cline { 2 - 5 } & $\mathrm{Total}$ & $\mathrm{kWh}$ prim/kWh final & 1.037 & 2.368 \\
\hline \multirow{2}{*}{$\begin{array}{c}\text { Emissions } \\
\text { factors }\end{array}$} & $\mathrm{CO}_{2}$ & $\mathrm{~g} / \mathrm{GJ}$ & 0.018 & 0.331 \\
\cline { 2 - 5 } & $\mathrm{NO}_{\mathrm{x}}$ & $\mathrm{g} / \mathrm{GJ}$ & 91 & - \\
\cline { 2 - 5 } & $\mathrm{SO}_{2}$ & $\mathrm{~g} / \mathrm{GJ}$ & 11 & - \\
\hline
\end{tabular}

Table A5. Social cost parameters.

\begin{tabular}{ccc}
\hline Emission Cost Per Pollutant & Units & Biomass \\
\hline $\mathrm{CO}_{2}$ & $€ / \mathrm{T}$ & 17.0 \\
\hline $\mathrm{SO}_{2}$ & $€ / \mathrm{kg}$ & 7.05 \\
\hline $\mathrm{NOx}$ & $€ / \mathrm{kg}$ & 4.96 \\
\hline $\mathrm{PM}_{2.5}$ & $€ / \mathrm{kg}$ & 74.4 \\
\hline
\end{tabular}

\section{References}

1. IEA. The Future of Cooling; International Energy Agency: Paris, France, 2018.

2. Yalew, S.G.; van Vliet, M.T.H.; Gernaat, D.E.H.J.; Ludvig, F.; Miara, A.; Park, C.; Byers, E.; de Cian, E.; Piontek, F.; Iyer, G.; et al. Impacts of climate change on energy systems in global and regional scenarios. Nat. Energy 2020, 5, 794-802. [CrossRef]

3. Berardi, U.; Jafarpur, P. Assessing the impact of climate change on building heating and cooling energy demand in Canada. Renew. Sustain. Energy Rev. 2020, 121, 109681. [CrossRef]

4. North American Regional Climate Change Program. Available online: http://www.narccap.ucar.edu/ (accessed on 12 March 2021).

5. Morna, I.; van Vuuren, D.P. Modeling global residential sector energy demand for heating and air conditioning in the context of climate change. Energy Policy 2009, 37, 507-521.

6. RHC-Platform. 2050 Vision for a 100\% Renewable Heating and Cooling in Europe; RHC-Platform: Brussels, Belgium, 2019.

7. Lund, H.; Werner, S.; Wiltshire, R.; Svendsen, S.; Thorsen, J.E.; Hvelplund, F.; Mathiesen, B.V. 4th Generation District Heating (4GDH): Integrating smart thermal grids into future sustainable energy systems. Energy 2014, 68, 1-11. [CrossRef]

8. Buffa, S.; Cozzini, M.; D'Antoni, M.; Baratieri, M.; Fedrizzi, R. 5th generation district heating and cooling systems: A review of existing cases in Europe. Renew. Sustain. Energy Rev. 2019, 104, 504-522. [CrossRef]

9. Ziemele, J.; Vigants, G.; Vitolins, V.; Blumberga, D.; Veidenbergs, I. District Heating Systems Performance Analyses. Heat Energy Tariff. Environ. Clim. Technol. 2014, 13, 32-43. [CrossRef]

10. Sarma, U.; Bažbauers, G. District heating tariff component analyses for tariff benchmarking model. Energy Procedia 2017, 113, 104-110. [CrossRef]

11. Fortum. Benchmarking District Heating in Hungary, Poland, Lithuania, Estonia and Finland. 2011. Available online: https:/ / erranet.org/download/benchmarking-district-heating-hungary-poland-lithuania-estonia-finland-2/ (accessed on 12 March 2021).

12. Noussan, M. Performance indicators of District Heating Systems in Italy-Insights from a data analysis. Appl. Therm. Eng. 2018, 134, 194-202. [CrossRef]

13. Ecoheat4cities. Guidelines for Technical Assessment of District Heating Systems; Ecoheat4cities: Watford, UK, 2012.

14. Kveselis, V.; Dzenajavičienè, E.F.; Masaitis, S. Analysis of energy development sustainability: The example of the Lithuanian district heating sector. Energy Policy 2017, 100, 227-236. [CrossRef]

15. Ghafghazi, S.; Sowlati, T.; Sokhansanj, S.; Melin, S. A multicriteria approach to evaluate district heating system options. Appl. Energy 2010, 87, 1134-1140. [CrossRef]

16. Pakere, I.; Lauka, D.; Dolge, K.; Vitolins, V.; Polikarpova, I.; Holler, S.; Blumberga, D. Climate Index for District Heating System. Environ. Clim. Technol. 2020, 24, 406-418. [CrossRef]

17. Volkova, A.; Mašatin, V.; Siirde, A. Methodology for evaluating the transition process dynamics towards 4th generation district heating networks. Energy 2018, 150, 253-261. [CrossRef]

18. Wedistrict Project. Available online: https:/ / www.wedistrict.eu/ (accessed on 12 March 2021). 
19. IEA. Projected Cost of Generating Electricity, 2015 ed.; Organisation for Economic Co-operation and Development/International Energy Agency, Organisation for Economic Co-Operation and Development/Nuclear Energy Agency: Paris, France, 2015.

20. Afgan, N.H.M.G.; Carvalho, M.G.; Hovanov, N.V. Energy system assessment with sustainability indicators. Energy 2000, 28, 603-612.

21. Lu, Y.; Khan, Z.A.; Alvarez-Alvarado, M.S.; Zhang, Y.; Huang, Z.; Imran, M. A Critical Review of Sustainable Energy Policies for the Promotion of Renewable Energy Sources. Sustainability 2020, 12, 5078. [CrossRef]

22. EC. A European Strategic Long-Term Vision for a Prosperous, Modern, Competitive and Climate Neutral Economy, COM (2018) 773 Final. Available online: https:/ / eur-lex.europa.eu/legal-content/EN/TXT/?uri=CELEX:52018DC0773 (accessed on 12 March 2021).

23. Khomenko, S.; Cirach, M.; Pereira-Barboza, E.; Mueller, N. Premature mortality due to air pollution in European cities: A health impact assessment. Lancet 2021, 5, 121-134.

24. Werner, S. International review of district heating and cooling. Energy 2017, 137, 617-631. [CrossRef]

25. Averfalk, H.; Ingvarsson, P.; Persson, U.; Gong, M.; Werner, S. Large heat pumps in Swedish district heating systems. Renew. Sustain. Energy Rev. 2017, 79, 1275-1284. [CrossRef]

26. ISO 52000. Energy Performance of Buildings-Overarching EPB Assessment; ISO: Geneva, Switzerland, 2017.

27. IPCC. 2019 Refinement to the 2006 IPCC Guidelines for National Greenhouse Gas Inventories; IPCC: Geneva, Switzerland, 2019.

28. EEA. EMEP/EEA Air Pollutant Emission Inventory Guidebook 2019; European Environmental Agency: Copenhagen, Denmark, 2019.

29. Directive 201/844/EU of the Parliament and of the Council of 19 May 2010 on the Energy Performance of Buildings. 2018. Available online: https://www.buildup.eu/en/practices/publications/directive-201031eu-energy-performance-buildingsrecast-19-may-2010 (accessed on 12 March 2021).

30. Directive EU 2018/2001 of the European Parliament and of the Council of 11 December 2018 on the Promotion of the Use of Renewable Energy from Renewable Sources. 2018. Available online: https:/ / eur-lex.europa.eu/legal-content/EN/TXT/PDF/ ?uri=CELEX:32018L2001\&from=fr (accessed on 12 March 2021).

31. Ea Energy Analyses. Renewable Energy Cost and Benefits for Society (RECABS)-Final Technical Report; Ea Energy Analyses: København, Denmark, 2007.

32. NREL. Simple Levelized Cost of Energy (LCOE) Calculator Documentation. Available online: https://www.nrel.gov/analysis/ tech-lcoe-documentation.html (accessed on 12 March 2021).

33. Danish Energy Agency. Finding You Cheapest Way to a Low Carbon Future-The Danish Levelized Cost of Energy Calculator. Available online: https://ens.dk/sites/ens.dk/files/Globalcooperation/vejledning_lcoe_calculator.pdf (accessed on 12 March 2021).

34. Gudmundsson, O.; Thorsen, J.E.; Zhang, L. Cost analysis of district heating compared to its competing technologies. WIT Trans. Ecol. Environ. 2013, 176, 3-13.

35. Popovski, E.; Fleiter, T.; Santos, H.; Leal, V.; Fernandes, E.O. Technical and economic feasibility of sustainable heating and cooling supply options in southern European municipalities: A case study for Matosinhos, Portugal. Energy 2018, 153, 311-323. [CrossRef]

36. Schindel, D.T. The social cost of atmospheric release. Clim. Chang. 2015, 130, 313-326. [CrossRef]

37. EEA. Cost of Air Pollution from European Industrial Facilities 2008-2012; European Environment Agency: København, Denmark, 2014; Volume 20.

38. David, A.; Vad Mathiesen, B.; Averfalk, H.S.; Werne, S.; Lund, H. Heat Roadmap Europe: Large-Scale Electric Heat Pumps in District Heating Systems. Energies 2017, 10, 578. [CrossRef] 